\title{
The Classical Model of Science: a millennia-old model of scientific rationality
}

\author{
Willem R. de Jong • Arianna Betti
}

Received: 25 July 2007 / Accepted: 26 March 2008 / Published online: 18 November 2008

(C) The Author(s) 2008. This article is published with open access at Springerlink.com

\begin{abstract}
Throughout more than two millennia philosophers adhered massively to ideal standards of scientific rationality going back ultimately to Aristotle's Analytica posteriora. These standards got progressively shaped by and adapted to new scientific needs and tendencies. Nevertheless, a core of conditions capturing the fundamentals of what a proper science should look like remained remarkably constant all along. Call this cluster of conditions the Classical Model of Science. In this paper we will do two things. First of all, we will propose a general and systematized account of the Classical Model of Science. Secondly, we will offer an analysis of the philosophical significance of this model at different historical junctures by giving an overview of the connections it has had with a number of important topics. The latter include the analytic-synthetic distinction, the axiomatic method, the hierarchical order of sciences and the status of logic as a science. Our claim is that particularly fruitful insights are gained by seeing themes such as these against the background of the Classical Model of Science. In an appendix we deal with the historiographical background of this model by considering the systematizations of Aristotle's theory of science offered by Heinrich Scholz, and in his footsteps by Evert W. Beth.
\end{abstract}

Keywords Axiomatics - Classical Model of Science - Scientific explanation · Aristotle $\cdot$ Logic of Port-Royal · Bolzano

W. R. de Jong $(\bowtie) \cdot$ A. Betti

Faculteit der Wijsbegeerte, Vrije Universiteit Amsterdam,

De Boelelaan 1105, 1081 HV Amsterdam, The Netherlands

e-mail: wr.de_jong@ph.vu.nl 


\section{The Classical Model of Science as an ideal of scientific explanation}

In the following we will speak of a science according to the Classical Model of Science as a system $S$ of propositions and concepts (or terms) which satisfies the following conditions:

(1) All propositions and all concepts (or terms) of $S$ concern a specific set of objects or are about a certain domain of being $(s)$.

(2a) There are in $S$ a number of so-called fundamental concepts (or terms).

(2b) All other concepts (or terms) occurring in $S$ are composed of (or are definable from) these fundamental concepts (or terms).

(3a) There are in $S$ a number of so-called fundamental propositions.

(3b) All other propositions of $S$ follow from or are grounded in (or are provable or demonstrable from) these fundamental propositions.

(4) All propositions of $S$ are true.

(5) All propositions of $S$ are universal and necessary in some sense or another.

(6) All propositions of $S$ are known to be true. A non-fundamental proposition is known to be true through its proof in $S$.

(7) All concepts or terms of $S$ are adequately known. A non-fundamental concept is adequately known through its composition (or definition).

We will call conditions (1)-(7) taken together the Classical Model of Science (also, for short: the Model). A science that is or is expected to be organized according to these conditions we will call a real or a proper science. The Classical Model of Science is a recent reconstruction a posteriori of the way in which philosophers have traditionally thought about what a proper science and its methodology should be, and which is largely set up, as it were, by abduction. The cluster (1)-(7) is intended, thus, to sum up in a fairly precise way the ideal of scientific explanation philosophers must have had in mind for a very long time when thinking about science.

The Classical Model of Science encodes an ideal of scientific knowledge as cognitio ex principiis. A proper science according to this Model has the structure of a more or less strictly axiomatized system with a distinction between fundamental and nonfundamental elements. Note that the sense in which a proper science according to the Model is an 'axiomatized system' is broader than the one the word usually has. One way to put this is to say that the Model leaves room, as it will become clear, both for a system of propositions ordered by relations of grounding or deducibility (axiomatics proper) and for a system of terms or concepts ordered by means of definitions. As we shall see, to this distinction other important distinctions are connected, among others that between knowledge of what is fundamental and knowledge of what is not fundamental and that between analytic and synthetic method, that is, respectively, going backwards from what is not fundamental to what is (more) fundamental (regressus), and going forward from what is (more) fundamental to what is less fundamental (progressus). ${ }^{1}$

A very important distinction is that between the order of being or ordo essendi and the order of knowing or ordo cognoscendi, that is the question of the distinction between on the one side what is prior in nature or reality, linked to real or objective

$\overline{1}$ On the regressive conception of analysis, see Beaney (2007). 
grounds (aitiai) of things, and on the other side the question of what is prior in relation to us, linked to the (subjective) grounds of cognition. Although in history the two orders often have not been kept distinct, the distinction between them is so important that we incorporated it in the Model: the conditions (1)-(5) relate primarily to the ordo essendi, the conditions (6) and (7) regard instead typically the ordo cognoscendi. In addition to these notions numerous other ideas in the historical development of philosophy of science and scientific philosophy are significantly connected with the Model. In the continuation we will introduce and briefly examine some of them.

The history of the conceptualization and methodology of the Classical Model of Science knows three milestones: first of all, Aristotle's Analytica posteriora, especially book 1; secondly, the very influential so-called Logic of Port-Royal (1662), especially part IV: 'De la méthode', written mainly by Antoine Arnauld and relying in many respects on Pascal and Descartes; and finally Bernard Bolzano's Wissenschaftslehre (1837).

It is important to stress that although its sources go ultimately back to Aristotle, the Model is not meant to count as a faithful reconstruction of Aristotle's theory of science. The Model is rather an ideengeschichtlich interpretive framework that aims at capturing in a systematic way a standard paradigm of scientific rationality being largely an ideal, an ideal to which philosophers adhered throughout history, and only initially inspired by Aristotle. In particular, adherence to the Classical Model of Science has nothing to do with the question whether one should be an Aristotelian in matters of natural science. ${ }^{2}$ Noted 'anti-Aristotelians' like Hobbes and Descartes are adherents of some version of the Model.

The influence of the Model has been enormous for more than two millennia. It dominated in particular the philosophy of science of the sixteenth, seventeenth and eighteenth century, counting among its pronounced followers Newton, Pascal, Spinoza, Descartes, Leibniz, Wolff and Kant, and still later Bolzano, Husserl, Frege and Leśniewski, ${ }^{3}$ who was possibly its last great advocate. The point that the ideal we capture in the Model has been enormously influential has been stressed by a number of scholars in the past. ${ }^{4}$

As we have said, the Classical Model of Science is a reconstruction. Philosophers following the Model do not usually formulate their conception of science in a systematic and programmatic manner. The formulation coming closest to a systematization of the ideal of science we codify in the Model is perhaps the description of scientific method given in the Logic of Port-Royal, 'The scientific method reduced to eight main rules':

\footnotetext{
${ }^{2}$ For this reason the Model is dubbed here the 'Classical Model of Science' and not the 'Aristotelian Model of Science' as in de Jong (1996, 2001).

${ }^{3}$ See also de Jong (2008), Lapointe (2008), Korte (2008) and Betti (2008a).

${ }^{4}$ As Dijksterhuis claimed, demonstrative science in the classical sense served as the guiding principle for the foundation of seventeenth century mechanics and that part of physics which is based on it; cf. Dijksterhuis (1986, pp. 464-465). According to Randall "the whole great literature on method that fills the scientific writing of the seventeenth century is at bottom a series of footnotes to the Organon of Aristotle" (Randall 1961, p. 63). In line with Randall, Mancosu has argued that the classical notion of science not only shaped a great part of the philosophy of mathematics in the seventeenth century but also, with reference to Kant, Bolzano and Frege, that it kept its function afterwards; see Mancosu (1996, pp. 10, 92, 102).
} 


\section{Two rules concerning definitions}

1. Leave no term even slightly obscure or equivocal without defining it.

2. In definitions use only terms that are perfectly known or have already been explained.

2. Two rules for axioms

3 . In axioms require everything to be perfectly evident.

4. Accept as evident what need only a little attention to be recognized as true.

3. Two rules for demonstrations

5. Prove all propositions that are even slightly obscure, using in their proofs only definitions that have preceded, axioms that have been granted, or propositions that have already been demonstrated.

6. Never exploit the equivocation in terms by failing to substitute mentally the definitions that restrict and explain them.

\section{Two rules for method}

7. Treat things as much as possible in their natural order, beginning with the most general and the simplest, and explaining everything belonging to the nature of the genus before proceeding to particular species.

8. Divide each genus as much as possible into all its species, each whole into all its parts, and each difficulty into all its cases. ${ }^{5}$

Although the rules for definitions, axioms and demonstrations are borrowed virtually verbatim from Pascal, ${ }^{6}$ they also go back in part to Descartes, as becomes evident if one compares the four famous rules of method from the Discours de la méthode and the Regulae ad directionem ingenii of which Arnauld possessed a copy. The 'natural order' of Rule 7 is obviously that of the ordo essendi. It is however remarkable that this order 'of things' seems to be largely dominated by the epistemic ordering, the ordo cognoscendi. This is apparent in Rules 2 and 3: in the latter, for instance, the ontological requirement concerning axioms, that is, that there must be fundamental propositions (cf. 3a in our Model), is not distinguished from the epistemic requirement that axioms should be evident.

As mentioned above, the eight rules are a special case because they constitute a rare attempt at formulating explicitly the ideal of science codified in the Model. One would often seek in vain similar systematizations in the writings of philosophers who are nevertheless followers of the very same ideal of science. Lack of explicit mention is hardly surprising if one takes into account that the ideal of science expressed in the Model was a standard for many centuries. The fact that many philosophers followed the Model in an implicit way, however, makes it difficult for interpreters today to see the important role that the Model played in their thought. We believe the risk of not giving the Model its due weight is one historians of philosophy should not run. As the following should make clear, there are a number of important notions that are not only significantly related to the Model but that are fully understandable only against

\footnotetext{
5 Arnauld and Nicole (1662, p. 334).

6 Pascal (1965, IX, pp. 240-290). The specific rules for method have a strong Ramist flavour, especially in their references to genera and species.
} 
its background such that they would remain murky or be of lesser significance, or be left floating about if abstracted from it.

We will discuss some of these notions in Sect. 3. First, in Sect. 2, below, we comment on the seven conditions that make up the Model. Before we do this, however, it is worth mentioning that systematizations of this ideal of science similar to the one we offer here have begun to appear only recently. The first and best known is to be found in Scholz's 'Der Axiomatik der Alten' (1930). Scholz's characterization was followed by Beth's, Dijksterhuis's and, finally, de Jong's systematizations, ${ }^{7}$ which have formed the basis for the Model. We will say more on the historiographical development of the Model as a framework in the Appendix below. Here we would just like to note that Scholz, differently from what Beth and Dijksterhuis were to do later, did not yet see his model as an interpretative tool to gain insight in the way in which many philosophers looked at science and its structure across the centuries. Scholz intended his model primarily as a reconstruction and a summary of Aristotle's own conception of science, taken to be also characteristic of "classical [i.e. Greek] axiomatics". Unlike Scholz, and more in the spirit of Beth and Dijksterhuis, we see the Model as a conceptual, interpretative framework enabling us to get a firmer grasp on a number of issues debated through the history of philosophy.

\section{The Classical Model of Science: some stipulations and comments}

In the Classical Model of Science a proper science is characterized by means of propositions, concepts (or terms) and objects or being(s). These expressions are supposed to function as determinables, for history knows also alternative notions: instead of propositions, theses, judgments, thoughts (Gedanken), sentences and statements may occur; instead of concepts, terms, ideas, (re)presentations (Vorstellungen); instead of objects (Gegenstände), things, (real) entities, etc.

$A d$ (1). Call condition 1 the 'Domain Postulate'. The function of this postulate is to prescribe that sciences possess a certain homogeneity, an internal unity on the basis of which we can delimit them from one another. The internal unity is provided by a single specific domain constitutive for a science $S$. So, on a minimal note, by a certain domain of a science is meant what a science is about, the domain of investigation or the subject-matter of that science: some branch of knowledge, or some genus in Aristotle's sense (the highest specific genus of a science). This is a rather generic formulation and difficulties arise when we wish to get a grasp on the notion of the domain of a science less loosely characterized than this. ${ }^{8}$

A number of fundamental issues relate to this postulate. A first issue is the hierarchical disposition of (at least some) sciences, or subalternation, which is traditionally linked to discussions of Aristotle's prohibition-rule on kind-crossing (metabasis eis allo genos). A second issue is the connection between the domain of a science and a particular source of knowledge. This issue has bearing also on conditions (5) through

\footnotetext{
7 Cf. Scholz (1930/1975, pp. 50-52, 64); Beth (1950, pp. 27-41); Beth (1965, pp. 31-51); Dijksterhuis (1986, pp. 41-42); de Jong (2008, 1996, 2001).

8 See Cantú (2008).
} 
(7) and it is discussed, for instance, by Kant and also by Frege, who speaks of the domains of logic and geometry as related to different sources of knowledge. The Domain Postulate lies at the core of debates about whether disciplines like logic and metaphysics should or should not be considered real sciences.

Ad (2a) and (3a). The fundamental propositions and often also the fundamental concepts of a real science are called principles. One usually assumes that the number of principles is finite, and often quite restricted. Sometimes definitions, or propositions corresponding to definitions (see $2 \mathrm{~b}$ ), are also conceived of as principles.

$A d$ (2b). Condition (2b) encodes what we call the 'Composition Postulate'. One common way in which this postulate has been specified is as (what we will call) the 'Postulate of Classical Definition'. According to this postulate, concepts are understood as composed according to the traditional model of definitio per genus proximum et differentiam specificam. Aristotle and the authors of the Logic of Port-Royal for instance conceive of definitions in this way as a matter of course. But philosophers like Bolzano and Frege reject this model as a general model for definitions. ${ }^{9}$

$A d$ (3). Conditions (3a) and (3b) correspond to the Proof Postulate. Propositions of $S$ that can be (or have to be) proved - that is, the non-fundamental propositionsare sometimes called theorems or theses. One way in which the Proof Postulate has been determined is as the Deducibility Postulate, i.e. all non-fundamental propositions of $S$ can be deduced (or follow logically) from the fundamental propositions (and definitions) of $S$. Note, however, that contrary to what Scholz and Beth (see the Appendix below) claim, deducibility is too weak a construal of the Proof Postulate according to most adherents of the Classical Model of Science. True, Frege identifies the Proof Postulate with (his version of) the Deducibility Postulate, but usually more is required: proving $p$ in $S$ means drawing an inference that constitutes an explanative demonstration, a real or objective grounding of $p$. Aristotle distinguished between a syllogism and a demonstrative or scientific syllogism, ${ }^{10}$ as providing, as the Medievals would put it, respectively a demonstratio quia, that is, that things are such and such, and a demonstratio propter quid, that is, why things are such and such. This distinction corresponds also to the distinction between proof a posteriori, or starting from effects (demonstratio ab effectibus), and proof a priori, as proof starting from causes (demonstratio ex causis). The proof a priori was also considered as the highest sort of demonstration (demonstratio potissima, Aristotle's apodeixis aplôs). ${ }^{11}$ In Bolzano this distinction is reflected in the distinction between the relation of Abfolge and that of Ableitbarkeit between propositions. It is the first kind of demonstration, and not the second, that the Proof Postulate is about. ${ }^{12}$

\footnotetext{
9 Cf. Frege (1884, pp. 100); Bolzano (1837, §148).

10 Aristotle (Apo 71b20-22, 78a23-b3). See also: Mignucci (1975, 292ff.).

11 But note that demonstratio propter quid is sometimes distinguished from demonstratio potissima, so that three demonstrative Aristotelian procedures are mentioned (quia, propter quid and potissima). This is the case in the School of Padua where this issue is intertwined both with the distinction between regressus and progressus and with that between ordo essendi and ordo cognoscendi. Cf. Vasoli (1984, pp. 55, 57, $65,71)$.

12 Bolzano (1837, $\S 113,155,162,168,177,198 f f$.$) . On Abfolge see Tatzel (2002), in particular$ Sect. 4 on the difference between grounding and deducibility.
} 
Arnauld's and many others' criticism of the use of reductio ad absurdum as not producing knowledge propter quid should also be seen in connection with the Proof Postulate. The same motivation underlines Kant's critical position respecting reductio ad absurdum in transcendental philosophy or metaphysics. ${ }^{13}$ An important issue connected to the Proof Postulate and the distinction between demonstratio quia and demonstratio propter quid is its application to the method of analysis (or resolutio) and synthesis (or compositio), especially in the form which it takes in the Renaissance (and chiefly in Zabarella) and in the Early Modern Period from Descartes to Kant.

$A d$ (2) and (3). The four conditions (2a) (2b) (3a) and (3b) capture what we shall call the 'Postulate of Order', which guarantees the coherence of propositions as well as that of concepts.

More precisely, together with the Domain Postulate (1), conditions (2a) and (2b) require the systematic coherence of a science $S$ at the level of concepts, while together with (1) conditions (3a) and (3b) require the systematic coherence of $S$ at the level of propositions. Recall the eight rules of the Logic of Port-Royal we mentioned above: the rules of method, that is, Rule 7 and Rule 8, correspond to the Postulate of Order. Note that while Pascal and Arnauld distinguished sharply the propositional from the conceptual ordering of a classical science, other important followers of the Model did not. Among the latter are Descartes-by whom, as we already mentioned, the eight rules were in part inspired-and Aristotle. ${ }^{14}$

Ad (4). Condition 4 answers to the Truth Postulate. This postulate does not presuppose any particular conception of truth. In particular it does not require that the truth at issue be understood along correspondentist lines. Virtually any conception of truth, however modest, would in fact do. ${ }^{15}$ What exactly a minimal requirement respecting truth is supposed to be in this context might be a matter of contention; what is meant, however, is certainly more than rhetorical talk of truth. The way in which we construe this postulate would thus exclude, for instance, some conventionalist approaches in which truth has no role in the choice between rival theories.

$A d(5)$. Aristotle sees universality and necessity as intrinsically connected, followed by Kant who characterizes a priori knowledge as "necessary and strictly universal". ${ }^{16}$ In many authors universality and necessity do indeed come close, as to suggest a unification of these two notions into a single requirement, as we do in (5). But one might, for the sake of analysis, distinguish these two, and speak of (5) as encoding both a Universality Postulate and a Necessity Postulate.

The Universality Postulate requires at first only that the propositions of $S$ be general or universal. But it often involves more, for instance that the propositions of $S$ should be maximally general, as demanded by Aristotle's notion of strict universality (kathólou), and in the sixteenth century by the last of the three 'golden' laws of Petrus Ramus,

\footnotetext{
13 Arnauld and Nicole (1662, pp. 328-329). Cf. Mancosu (1991). See also: Mancosu (1996, pp. 105-117). Kant (1787, A 789/B 817).

14 Cf. Granger (1976, pp. 83-94).

15 The possible exception is Tarski's theory of truth. On the relationship between Tarski's semantics and the Model see Betti (2008b).

16 Kant (1787, B4).
} 
which he borrowed from the first book of Analytica posteriora. ${ }^{17}$ Ramus's third law is known as the lex de universali, lex kathólou or lex sapientiae; it requires that the universal be dealt with universally and the particular particularly. This means that a property of a genus cannot be ascribed to a species and vice versa. The proposition that the sum of the angles of an equilateral triangle is identical to two right angles is thus not a theorem (or a demonstrable proposition of Euclidean geometry), because this property belongs to all triangles and not just to equilateral triangles. ${ }^{18}$

The Necessity Postulate requires that any proposition of a real science is necessary in some sense. It is rather difficult to explain in a general way what this postulate means. Part of the problem is that it is often unclear whether it is necessity in the sense of the ordo cognoscendi that is meant, which amounts to aprioricity and/or certainty, or necessity in the sense of the ordo essendi, that is aprioricity as essential predication or praedicatio per se. Although the distinction between the ordo essendi and the ordo cognoscendi is particularly stressed in Bolzano, it is already clearly found in Aristotle. As we already indicated, however, the two ordines often mingle in different and rather opaque ways.

$A d(6)$ and (7). Conditions (6) and (7) make clear that the Classical Model of Science offers a theory for the justification as well as for the explanation of scientific knowledge that often involves a form of (epistemic) foundationalism. Foundationalism is taken here in a general sense as the doctrine that all knowledge is ultimately based on, or has to be ultimately justified in terms of fundamental knowledge. If for the moment we disregard knowledge of concepts and concentrate on propositional knowledge, necessary requirements for propositional knowledge can be given as follows: $p$ is known implies, firstly, that $p$ is true and, secondly, that $p$ is justified in some sense or another.

Embedded in conditions (6) and (7) we find what we will call the 'Knowledge Postulate', i.e. any proposition of $S$ is known to be true and any concept of $S$ is adequately known. The Knowledge Postulate is a general one and leaves open how justification works. Given the difference between fundamental and non-fundamental elements, the Model has to accommodate two kinds of justification, one for the fundamental, and one for the non-fundamental elements. The second part of conditions (6) and (7) taken together tells us how justification works for non-fundamental elements. It forms the epistemic counterpart of conditions ( $2 b)$ and ( $3 b)$ and will be referred to as the more specific Postulate of Grounded Knowledge. Grounded knowledge is to be intended as knowledge propter quid or demonstrative knowledge as explained above. Scientific knowledge according to the Postulate of Grounded Knowledge is knowledge which is also explanative; in it the ordo cognoscendi matches the ordo essendi.

Fundamental items have a special position. How are they justified? What is their precise epistemic status? The Knowledge Postulate leaves open precisely these questions.

\footnotetext{
17 Ramus' first law—-the lex de omni, lex katà pantós or lex veritatis—corresponds to the Truth Postulate and to the Necessity Postulate. The second law-the lex per se, lex kath'hautó, lex homogenei or lex justitiae - is instead linked with what here is indicated as the Domain Postulate. Cf. Aristotle (Apo 73a23ff.), and Ong $(1979,258 f f$.$) . See also Verdonk (1966, 322ff.) .$

18 Aristotle (Apo 73b30-74a18); Arnauld and Nicole (1662, p. 312); Bolzano (1837, §447). See also de Jong (2001, p. 347).
} 
A very strong option in this respect is invoking what we shall call the Evidence Postulate, i.e. the fundamental propositions and fundamental concepts of $S$ are known immediately or by themselves. The way in which 'immediately known' or 'known by itself' is intended here is that the principles have to be self-evident or the result of intuitive knowledge, or both.

Unlike Scholz and Beth, we do not regard this postulate as structurally embedded in the classical concept of science as presented here. ${ }^{19}$ Nevertheless, it has to be admitted that until the second half of nineteenth century almost everyone sees the principles of Euclidean geometry, the example par excellence of a real science, automatically as self-evident.

Many of the older adherents of the Model, moreover, among others Spinoza, Pascal and the logic of Port-Royal, seem to accept the Evidence Postulate not only for the mathematical sciences but for all sciences. ${ }^{20}$ But there are notable exceptions, even concerning a priori sciences (Kant affords an instance). In the first Kritik only "principles, in so far as they are immediately certain", ${ }^{21}$ like those of mathematics, are labelled as axioms, and the self-evidence of principles which are axioms is guaranteed by the faculty of intuition, especially intuition a priori. Principles that are not axioms are called 'discursive principles'. According to Kant metaphysics has discursive principles, that is, principles that "require a deduction". 22

With the rise of modern physics not only the Evidence Postulate but also the Knowledge Postulate became more and more problematic, at least in application to the empirical sciences. The question regarded the rising insight that procedures like empirical induction do not lead to the strong sense of knowledge implying truth.

\section{On the scope, place and role of the Classical Model of Science}

A rather intricate issue connected to the significance of the Model is the following. The Model can be considered as a normative guide for finding scientific truths, that is, as related to the ars inveniendi (methodus inventionis) or, as we are used to say, the context of discovery; or it can approached as an organized system of known truths, that is, it can be seen as related to the context of justification.

A further distinction that one might want to make within the latter is that between methodus iudicii and methodus doctrinae as this distinction is for instance found in Gassendi, that is, "concerning judicious analysis and assessment of what has been discovered", i.e. the context of justification in the strict sense, and "formulation of

\footnotetext{
19 See Bolzano (1837, §487). Cf. Aristotle (Apo 99b20-100b17); see especially the comment of Barnes on this chapter concerning the principles of physics: (Barnes, 1994, pp. 267-270).

20 Also, one might think that a good example would be Descartes: in his famous method the distinction between distincte (or claire) and confuse (or obscure) ideas plays an important role. In the first rule of method, the so-called evidence rule, evidence has direct bearing on what is (fully) claire and distincte. However, in this rule it is not very clear whether or how evidence (that we might bring together with the Postulate of Grounded Knowledge) has to be distinguished from the self-evidence of principles (the Evidence Postulate as presented here). Cf. Descartes (1637, VI 18).

21 Kant (1787, A 732/B 760).

22 Kant (1787, A 733/B 761).
} 
the material in a manner appropriate for teaching it to someone else". ${ }^{23}$ Some have interpreted Aristotle's method in the Analytica posteriora as belonging primarily to the methodus doctrinae, ${ }^{24}$ and in the Logic of Port-Royal, likewise, the Model surfaces in the context of the méthode de doctrine or méthode de composition, "the most important method, since it is the one used to explain all the sciences". ${ }^{25}$ The two, methodus iudicii and methodus doctrinae, may very well differ: Bolzano but also for instance Arnauld and Wolff acknowledged that a science is not always taught in keeping with its objective structure. ${ }^{26}$ Actually, deviation from the objective or natural order of a science is seen sometimes as desirable or necessary for the sake of an adequate presentation of a science in a textbook.

This suggests that further complications may ensue on this point. If we take the Model as regarding primarily the context of justification, this might go two ways: in the sense of the ordo essendi and in that of the ordo cognoscendi. In other words, the Model might be taken to pertain in the first place to an ontological organization of truths in the sense of the ordo essendi, but it might also be taken to pertain to an epistemic organization of truths in the sense of the ordo cognoscendi (if it is possible to apply the distinction).

Another issue having a problematic nature is that of the extent to which in a proper science $S$ one can appeal to principles situated outside $S$. For in the context of a science $S$, appeal is sometimes made to other, more general, principles that have their place outside $S$, one important example being the appeal to propositions not belonging to $S$ to prove propositions of $S$. Aristotle distinguished common (or non-domain-specific) principles from proper (or domain-specific) principles. Common principles are those through which science is carried out, specific principles are those about which science is done. ${ }^{27}$

This distinction makes sense in the light of Aristotle's notion of subalternation of sciences to one another briefly mentioned above. If a science $S_{1}$ is subalternated to science $S_{2}$, the proper principles of $S_{1}$ must concern a specific domain of things (condition (1)). But whereas they may belong to $S_{2}$, the common principles do not belong to $S_{1}$ as such. In $S_{1}$, however, they can be used to prove theorems. Not all common principles must belong to one or the other science in particular, no matter how abstract the science is taken to be: some transcend even all categories (let alone the specific domain of a science). These transcategorial principles are the so-called

\footnotetext{
23 Cf. Gassendi (1658, p. 70).

24 See e.g. Barnes (1975, p. 85): "In developing the theory of demonstration and in constructing his notion of demonstrative science, Aristotle was not telling the scientist how to conduct his research. ... The theory of demonstration offers a formal account of how an achieved body of knowledge should be represented and taught".

25 Arnauld and Nicole (1662, p. 306).

26 Arnauld and Nicole (1662, p. 330). Cf. Wolff (1713, p. 225); Bolzano (1837, §§394, 401, 486).

27 Cf. Aristotle (Apo 88b28); Granger (1976, p. 81).
} 
ultimate principles, what we now identify as strong theorems of classical logic, such as the principle of contradiction or the principle of excluded middle. ${ }^{28}$

Strictly linked to the latter is yet another problematic issue. One might be puzzled that the ultimate principles are usually not taken to belong to any particular science, for one might think they belong to logic. But whether logic also constitutes a real science itself is both a difficult and a particularly interesting issue. For Frege, Bolzano and Leśniewski this is certainly the case, but for Aristotle and for most thinkers until Kant included (with the possible exception of Leibniz) logic was often not a science properly, but rather an ars. ${ }^{29}$ It is currently a matter of debate when exactly the issue of whether logic should be considered a real science came to the fore as a point of critical discussion among the followers of the Model. What seems clear is that in the period from Aristotle through Kant logic is often considered to be not a science conforming to the Model but a system of formal rules. ${ }^{30}$ This remains the case not only if we take logic to be limited to Aristotle's term logic, that is, syllogistic, but also take it to comprehend as well the 'common' propositional principles that lie outside syllogistic, like the (logical) principle of contradiction.

At this point it may be worthwhile to mention an issue that is likely to be importantly connected with the emergence of a serious debate about logic as a proper science. There are in recent history two fundamental interpretations of the notion of domain, which our formulation of (1) accommodate, call them the semantic interpretation and the ontological interpretation. The ontological interpretation sees the highest specific genus of a science as a collection of objects: a science investigates the attributes of certain objects whose existence is assumed and which form the subject-matter of the science. The semantic interpretation takes the genus to be instead a collection of certain concepts or of certain terms, that is, expressions with a certain meaning. So, according to the semantic interpretation, the language in which a science is formulated is composed of terms with a definite meaning, and it is these terms, not their objects, which delimit the subject-matter of that science. The first philosopher to question seriously the ontological interpretation in favour of the semantic interpretation seems to have been Bernard Bolzano.

The question of which disciplines are to be considered real sciences connects directly to the general problem of the scope of the model, and in particular to two issues. The Model prescribes how a proper science must be built ideally but does not say anything about how many and which sciences should obey it and what relation they should have one to another. So the first issue is: are all sciences suitable to be proper sciences or is the application of the Model restricted to mathematical, exact,

\footnotetext{
28 Cf. Mignucci $(1965,1965$, Sect 46, in particular pp. 262-263, n. 33, 34). Note that the restriction-rule of metabasis of Apo 75a38ff. does not apply to the use of a common principle in a subordinated science. Cf. also Granger (1976, pp. 92-93).

29 To mention just one opinion, for Jacopo Zabarella logic is not a science because it treats only secundae intentiones, that is, concepts of concepts - and for its instrumental character is more similar to the arts. Cf. Vasoli (1984, p. 68). The example makes clear that the fundamental problem with logic as a real science is linked with the Domain Postulate.

30 Cf. Granger (1976, pp. 141-142). Husserl relates the Model to logic quite directly as a science; see Husserl (1990/1901, Sect. 3) in its context.
} 
deductive, rational or a priori sciences? ${ }^{31}$ Should natural sciences be proper sciences also, and be grounded starting from mechanics and physics, via chemistry and so to biology? And how about metaphysics or ethics?

The second issue concerns the (possible) relation between different sciences. The notion of subalternation indicates that sciences are often conceived of as hierarchically ordered, so that some sciences are grounded in other (more fundamental) sciences. ${ }^{32}$ The foundation of sciences in other sciences has been a constant and conspicuous concern in the history of philosophy. To mention a few outstanding names, grounding programs of this sort were conceived by the Neoplatonist Proclus; by Descartes, with his tree of the sciences in the introduction of Les principes de la philosophie (1644), by Newton in Philosophiae naturalis principia mathematica (1687); and by Kant, who in Metaphysische Anfangsgründen der Naturwissenschaft (1786) aims at grounding (Newtonian) physics in metaphysics. Furthermore, there is little doubt that the whole logicist enterprises of Frege, of Russell \& Whitehead's Principia mathematica and of Leśniewski is to be seen in this perspective.

A general issue regards the conceptual limits of the Model. What, in terms of the criteria to be satisfied, is the threshold beyond which a science $S$ should cease to be regarded as a real science? Must all the postulates mentioned in the explication given above (often not very specific) be obeyed? As we already mentioned, in all generality we tend to think that they must, as postulates can be interpreted in a stricter or looser way, but some conditions seem to be more central than others.

And yet another, even more general point is that, as is well-known, typological stances like ours face the danger of seeming excessively broad and ultimately uninformative. The problem can be summed up as one of whether the Model has the unfortunate consequences of labeling just about everyone as its follower. Indeed, very many thinkers adhered to it through history. But it is neither the case that everyone adhered to it nor is it the case that for the periods in which its dominance was crushing it is of no help to interpreters: on the contrary, the Model is a fruitful analytic tool. Its influence lasted until recently; having persisted at least to Leśniewski, it in fact extended far beyond what one might suspect at first glance. It is certain, however, that at a some point the Model was abandoned without being replaced by anything comparable. The abandonment took place progressively during a process in which not only the shape of the Model changed but also, first and foremost, its relation with many of the issues mentioned in this section, important turns in the development of sciences and a variety of factors.

\footnotetext{
31 Beth (1965, p. 37): "mathematics constitutes the classical example-practically the only one which is generally accepted as such —of a deductive science in the sense of Aristotle's theory. Aristotle himself takes his illustrations mainly from the mathematical sciences".

32 Aristotle seems to have restricted the question of subalternation to mathematical sciences, but through the centuries the discussion was either restricted to other sciences, the so-called mixed sciences (scientiae mediae, those falling between mathematics and the philosophy of nature), as in the Middle Ages, or broadened, as in some Italian Renaissance Aristotelians of the Padua School (bar Zabarella), to include the relationship between philosophy of nature and medicine (the discussion touched also on disciplines like alchemy and agriculture), or even the theoretical part of ethics and politics (scientia civilis). Cf. Mikkeli $(2002,309,313,316 f f$.$) .$
} 
The point just touched upon is far too important and complex to be discussed properly here. We can merely mention that highly relevant have been, arguably, the improved standard of rigor that logic enjoyed after Frege; the restriction to deductive sciences; the discovery of non-Euclidean geometry and the ensuing debate of what geometry, if any, was 'the true one'; pluralism in logic; Hilbert's formalistic turn in mathematics together with the debates on the notion of interpretation and meaningfulness of symbolism and the emergence of model-theoretical tools in semantics. ${ }^{33}$

\section{Appendix-Historiographical background}

As we have already had occasion to mention, the Model has had two main predecessors: the systematizations of Aristotle's theory of science given by Scholz and by Beth (followed by Dijksterhuis), reproduced here below. There are some differences between Scholz's and Beth's systematizations, and there are also important differences between them and our Model.

As to the latter differences, first of all, Scholz and Beth do not keep ordo essendi and ordo cognoscendi apart. Secondly, they both consider the Evidence Postulate to be a crucial requirement of this conception of science. Thirdly, both construe the Proof Postulate in a weak way as a Postulate of Deducibility, not of grounding or explanation.

The way in which Beth's and Scholz's approach differ is that Beth ascribes to his systematization an ideengeschichtlich role, while Scholz sees it as a reconstruction of Aristotle's theory of science in the first place. Beth's approach is more similar to ours, but not without qualifications, as we shall see.

\section{Aristotle's theory of science according to Scholz}

According to Scholz:

the kernel of Aristotle's theory [of science] is found in the first book of the Posterior analytics, and its essential contents are these:

(A) A science in Aristotle's sense is a sequence of sentences about the elements of some single domain (genos), having the following properties:

(1) the sentences [Sätze] of the sequence divide into primitive sentences or axioms (axiômata, archai, prôta) and theorems (theôrêmata);

(2) the terms [Begriffe] appearing in these sentences divide into primitive terms (archai, prôta) and derived terms (ta ek toutôn, 'the things dependent of these'; Apo I 10, 76a33).

\footnotetext{
33 In connection with the latter issue, and in view of the relevance that it acquires in Frege and Leśniewski, it is important to note that, as already said en passant, the terms of which the Model speaks are not meaningless inscriptions, graphic manifestations in need of interpretation in a model-theoretical sense: by 'terms' here meaningful expressions are meant. That this is how terms are intended is clear from the fact that 'terms' are a good substitute for 'concepts' in the general formulation of the Model. From another angle, this suggests, moreover, that a good deal of what interpreters have tried to couch in terms of van Heijenoort's and Hintikka's dichotomies 'logic as language versus logic as calculus' and 'language as universal medium versus language as calculus' and their interrelation with the Leibnizian ideals of characteristica universalis and calculus ratiocinator and similar projects of philosophical languages a priori, might be discussed more rewardingly in connection with the Model. For more details on this point see Betti (2008a) and Korte (2008).
} 
(B) The primitive sentences must satisfy the following conditions:

(1) they must be immediately evident, and thus indemonstrable;

(2) they must be adequate, in the sense that apart from them the rules of logic are all that is required for the proof of the theorems.

(C) The primitive terms must satisfy the following conditions:

(1) they must be immediately intelligible, and hence undefinable;

(2) they must be adequate, in the sense that apart from them certain conjunctive operations are all that is required for the construction of the derived terms.

(D) In order to preserve this elegant symmetry, and to postpone for as long as possible the darkest part of Aristotle's axiomatics, we reserve to the end the formulation of Aristotle's third requirement on primitive sentences, namely that they must be necessary propositions. ${ }^{34}$

Scholz claims that his scheme represents not only Aristotle's concept of science ("the kernel to Aristotle's theory"; a "reconstruction" of it), but also the old Greek axiomatic theory - "the study of the elements of any exact science, i.e. of any science taking mathematics as its pattern". Both are unified under the label "Aristotle's axiomatic theory" or "classical axiomatics". 35

Some parts of Scholz's description deserve comment. The first part of (B1) and that of $(\mathrm{C} 1)$ correspond to the Evidence Postulate (since evidence is here supposed to imply truth, B1 is also intended as taking care of our Truth Postulate). (B1) is for Scholz part and parcel of Aristotle's theory of science. It is unclear, however, how we are supposed to understand the second part of (B1). Scholz seems to take sentences which are evident to be thereby also indemonstrable. Yet are we supposed to take indemonstrability as indemonstrability in $S$ or indemonstrability tout court? While the first is more plausible, the second does not seem to square with Aristotle's ideal. Secondly, even if indemonstrability in $S$ is what Scholz means, it seems more correct to take evident propositions as those propositions that we do not need to prove (as Frege would say, nicht beweisbedürftig), rather than propositions we cannot prove.

Requirement D is puzzling. Scholz does not formulate the notion of necessity involved in D in any precise way. In fact, D functions for Scholz as a receptacle of diverse difficulties which remain after A, B and C, actually of anything that cannot be put anywhere else. Scholz also slots under D, for instance, Aristotle's claim that scientific demonstration or proof requires more than (logical) deducibility. Note that the problem with the notion of necessity in this connection is twofold: not only the primitive sentences but all sentences have to be necessary in some sense. As is apparent from D and A, however, Scholz sees a science $S$ as a collection of sentences in the first place not as a collection of both terms and sentences.

At a certain point in his paper Scholz states that nowadays the Evidence Postulate is replaced by the Postulate of Consistency. This rather strange aside suggests that Scholz's rather generic reconstruction of Aristotle's axiomatic conception of science

\footnotetext{
34 Scholz (1930/1975, pp. 52-53). See Detel (1993) for a recent critical assessment of Scholz's reconstruction of Aristotle's conception of science.

35 Scholz (1930/1975, pp. 50-52, 64).
} 
must have been partly determined by the approach and interests of 'modern axiomatics' à la Hilbert, where the fundamental propositions or axioms are supposed to offer by themselves an exhaustive determination of the fundamental terms of a theory. ${ }^{36}$ In the last two sections of his article Scholz does return explicitly to Hilbert's mathematics and modern axiomatics as opposed to classical axiomatics. The main difference between these two should be that modern axiomatics rejects condition D. ${ }^{37}$

In conclusion, although Scholz presents his analysis as valid for "a science in Aristotle's sense", he sees it primarily as a summary of the scientific view of Aristotle himself, which at the same time would be characteristic of "classical [i.e. Greek] axiomatics". He does not present his reconstruction as a model that can be used to yield insights into important aspects of the structure and the understanding of science during more than two thousand years.

2. Beth and the Model

In the footsteps of Scholz, Beth introduces his characterization of Aristotle's theory of science as follows:

The essentials of Aristotle's theory of science may be compressed into the following definition of 'deductive' — or, as Aristotle says, 'apodeictic' — 'science': A deductive science is a system $S$ of sentences, which satisfies the following postulates:

(1) Any sentence belonging to $S$ must refer to a specific domain of real entities;

(2) Any sentence belonging to $S$ must be true;

(3) If certain sentences belong to $S$, any logical consequence of these sentences must belong to $S$;

(4) There are in $S$ a (finite) number of terms, such that

(a) the meaning of these terms is so obvious as to require no further explanation;

(b) any other term occurring in $S$ is definable by means of these terms.

(5) There are in $S$ a (finite) number of sentences, such that

(a) the truth of these sentences is so obvious as to require no further proof;

(b) the truth of any other sentence belonging to $S$ may be established by logical inference starting from these sentences. ${ }^{38}$

Beth does not spend many words on this systematization nor does he comment much on how the postulates are supposed to be interpreted. The conditions (4a) and (5a) constitute the Evidence Postulate. Postulate (2) corresponds to our Truth Postulate. Postulate (1) is called by Beth the 'Reality Postulate' and (3) the 'Deductivity Postulate'. The latter is a rather specific version of the Deducibility Postulate mentioned above and implies that a science is closed under deduction.

\footnotetext{
36 Scholz (1930/1975, p. 51). Cf. Hilbert (1918, 407, 409ff.).

37 Scholz (1930/1975, pp. 58, 63-64).

38 Beth (1965, pp. 31-32); cf. Beth (1950, pp. 26-27). This definition is already to be found in Beth (1944, pp. 63-65). And even earlier in Beth (1943, pp. 55-56). Beth refers to various publications by Scholz, but not, surprisingly, to Scholz (1930). However, Beth (1950) and Beth (1965) explicitly refer to Scholz (1930) for a full account of Aristotle's theory of science.
} 
Unlike Scholz with his characterization, but like us with the Model, Beth uses his systematization as an interpretative framework to cast light on some interesting turning points in the history of science and scientific philosophy.

There are two important differences between our Model and Beth, however. First of all, Beth is chiefly interested in setting up a tool to "grasp the roots of the doctrinal divergences to which the results of modern research in foundations of mathematics and physical sciences have given rise". ${ }^{39}$ And the way in which he sets up his framework has indeed the explicit aim of capturing the ideal of science as it was before the seventeenth century:

Aristotle's theory of science postulates, ..., any science to be deductive, to start from obvious principles, and to have an empirical foundation. About 1600, it became more and more clear from scientific practice that sciences could hardly fulfil these three postulates at once. ${ }^{40}$

Upholding or denying the conjunction of these Postulates of Evidence, Deducibility and Reality, says Beth, becomes a watershed-however fuzzy its chronological contours - that separates Old and New ways of looking at science in the Modern Era. This brings us to the second difference, which is linked to what we consider to be an aberration: the Reality Postulate (which we do not find in this specific form in Scholz). This postulate has at least two infelicitous consequences. Firstly, the restriction of the Domain Postulate to domains of 'real entities' makes clear that Beth's systematization focuses primarily on the transformation of the ideal of science for empirical sciences, for we do not see how room is left for mathematics. Secondly, it also suggests a strongly realistic interpretation of the objects of a science.

On the basis of this framework Beth offers a picture of the development from 1600 onwards of two different types of science "which could successfully rival and even supersede the solid edifice of peripatetic science". On the one hand rational sciences are those in which ('Aristotle's') Postulates of Deducibility and Evidence hold, but not that of reality. On the other hand empirical sciences answer "to the requirement of empirical foundation", i.e. start "from experimental data and proceed by analysis". They conform "to the reality postulate, but not necessarily to the postulates of deducibility and evidence". 41 As such neither the empirical nor the rational sciences in the eyes of Beth would meet Aristotle's theory of science any longer. Moreover according to Beth, later on,

rational science turned farther away from Aristotle's ideal, by dropping his evidence postulate also. The development of non-euclidean geometry constituted the first move in this direction. ${ }^{42}$

Beth's picture is not in all respects satisfying. Dijksterhuis emphasizes, for instance, that Newton presents an axiomatization of mechanics which, at least in principle,

\footnotetext{
39 Beth (1950, p. 27 our emphasis); cf. Beth (1965, p. 31).

40 Beth (1950, p. 34).

41 Beth (1965, pp. 38, 47).

42 Beth (1965, pp. 47-48).
} 
still conforms to Aristotle's theory of science. The only qualification Dijksterhuis adds is that in this axiomatization principles are evident "or at least can be rendered plausible". 43

Notwithstanding important differences in aim between their frameworks, Beth, like Dijksterhuis, followed Scholz's reconstruction of Aristotle's conception of science rather uncritically. First of all, like Scholz Beth does not take the distinction between ordo essendi and ordo cognoscendi adequately into account. As a consequence, he could exploit his framework in the analysis of the development of both empirical natural and deductive sciences only to a very limited extent.

Furthermore, both Scholz and Beth overlooked almost completely a fundamental insight at the core of the Model: the idea of scientific knowledge as explanation from grounds. ${ }^{44}$ Scholz places the issue in his condition D, "the darkest part of Aristotle's axiomatics", with which Scholz does not associate any postulate and in which everything lands with which both Scholz and modern axiomatics cannot cope. Beth disregards the issue completely.

That he does so may be due ultimately to Beth's assimilation of ordo essendi and ordo cognoscendi, because explanation, a relation connected to the ordo essendi (objective grounding), is construed as or identified with justification, which is instead an epistemical relation at the level of the ordo cognoscendi (subjective or epistemic grounding).

Open Access This article is distributed under the terms of the Creative Commons Attribution Noncommercial License which permits any noncommercial use, distribution, and reproduction in any medium, provided the original author(s) and source are credited.

\section{References}

In J. Barnes (Trans. \& comm.) (1994). Posterior analytics. Oxford: Clarendon Press.

Arnauld, A., \& Nicole, P. (1662). La logique ou l'art de penser. In P. Clair \& F. Girbal (Eds.), (1993). Paris: Vrin. Quotations from J. V. Buroker (Ed. \& Trans.) (1996). Logic or the art of thinking. Cambridge: Cambridge University Press.

Barnes, J. (1975). Aristotle's theory of demonstration. In Barnes et al. (Eds.) (pp. 65-87).

Barnes J., Schofield, M. \& Sorabji, R. (1975). Articles on Aristotle. I. Science. London: Duckworth.

Barnes. (1994). Commentary. In Aristotle, Posterior analytics J. Barnes (Trans. \& comm.) (pp. 81-271). Oxford: Clarendon Press.

Beaney, M. (2007). Analysis. In E. N. Zalta (Ed.), The Stanford Encyclopedia of Philosophy. Fall 2007 Edition. http://plato.stanford.edu/archives/fall2007/entries/analysis/.

Berg, J. (1962). Bolzano’s logic. Stockholm: Almqvist \& Wiksell.

\footnotetext{
43 Dijksterhuis (1986, p. 464). Dijksterhuis' description of Aristotle's demonstrative science (cf. ibid., 41-42) is a mixture of those of Scholz and Beth. In his bibliography are both Scholz (1930) and Beth (1944).

44 Failure to accommodate grounding adequately in Aristotle's theory of science has had unfortunate echoes. Following Scholz and Beth, in his deep study of Bolzano, Jan Berg systematizes Aristotle's conception in 9 rules and comes to the conclusion that Bolzano's conception of science agrees fundamentally with that of Aristotle (in the reading of Scholz and Beth), with the proviso that, among others, grounding (Abfolge) is substituted for deducibility (Ableitbarkeit). This makes clear that Berg takes mistakenly Abfolge, which is the most sophisticated attempt to conceptualize the notion of grounding ever put forward among the adherents of the Model, to be something new with respect to 'Aristotle's theory of science'. Cf. Berg (1962, pp. 161-164).
} 
Beth, E. W. (1943). Verleden en toekomst der wetenschappelijke wijsbegeerte. De Gids, 107, $55-67$.

Beth, E. W. (1944). De wijsbegeerte der wiskunde van Parmenides tot Bolzano. Antwerpen/Nijmegen: Dekker \& Van de Vegt.

Beth, E. W. (1950). Critical epochs in the development of the theory of science. The British Journal of the Philosophy of Science, 1, 27-41.

Beth, E. W. (1965). The foundations of mathematics. A study in the philosophy of science (2nd ed.). Amsterdam: North-Holland Publishing Company.

Betti, A. (2008a). Lesniewski's characteristicia universalis. Synthese doi:10.1007/s11229-008-9423-6.

Betti, A. (2008b). Polish axiomatics and its truth: On Tarski's Leśniewskian background and the Ajdukiewicz connection. In D. Patterson (Ed.), New essays on Tarski and philosophy. Oxford: Oxford University Press (in press).

Bolzano, B. (1837). Wissenschaftslehre. In L. Winter et al. (Eds.) (1969). Bernard Bolzano Gesamtausgabe. Reihe 1 (Vol. 11-14). Stuttgart-Bad Canstatt: Frommann-Holzboog.

Cantú, P. (2008). Aristotle's prohibition rule on kind-crossing and the definition of mathematics as a science of quantities. Synthese. doi:10.1007/s11229-008-9419-2.

de Jong, W. R. (2008). How is metaphysics as a science possible? The Review of Metaphysics, 39, $235-274$.

de Jong, W. R. (1996). Gottlob Frege and the analytic-synthetic distinction within the framework of the Aristotelian model of science. Kant-Studien, 87, 290-324.

de Jong, W. R. (2001). Bernard Bolzano, analyticity and the Aristotelian model of science. Kant-Studien, 92, 328-349.

de Jong, W. R. (2008). The analytic-synthetic distinction and the classical model of science: Kant, Bolzano and Frege. Synthese. doi:10.1007/s11229-008-9420-9.

Descartes, R. (1637). Discours de la méthode. In Ch. Adam \& P. Tannery (Eds.) (1964-1971). Oeuvres de Descartes (Vol. VI, pp. 1-78). Paris: Vrin.

Detel, W. (1993). Forschungsergebnisse. In Aristotle. Werke in Deutscher Übersetzung. Vol. III, part II/1: Analytica posteriora (pp. 263-334). H. Flashar (Ed.), W. Detel (Trans. \& comm.). Berlin: Akademie Verlag.

Dijksterhuis, E. J. (1986). The mechanization of the world-picture. Pythagoras to Newton. Princeton (N.J.): Princeton University Press. First published in Dutch: De mechanisering van het wereldbeeld (1950). Amsterdam: Meulenhoff.

Frege, G. (1884). Die Grundlagen der Arithmetik. Eine logisch-mathematische Untersuchung über den Begriff der Zahl (1961). Hildesheim: Georg Olms.

Gassendi, P. (1658). Institutio Logica 1658. H. Jones (Ed., Trans. \& Intr.). (1988). Assen: Van Gorcum.

Granger, G.-G. (1976). La théorie aristotélicienne de la science. Paris: Aubier Montagne.

Hilbert, D. (1918). Axiomatisches Denken. Mathematische Annalen, 78, 405-415.

Husserl, E. (1900/1901). Logische Untersuchungen. Halle a.d.S.: Max Niemeyer = Husserliana XVIII, XIX/1, XIX/2. The Hague/Boston/London: M. Nijhoff. J. N. Findlay (Trans.) (1970). London/Henley: Routledge \& Kegan Paul.

Kant, I. (1787). Kritik der reinen Vernunft (1998). Hamburg: Felix Meiner.

Korte, T. (2008). Frege's Begriffsschrift as a lingua characteristica. Synthese. doi:10.1007/ s11229-008-9421-8.

Lapointe, S. (2008). Bolzano, a priori knowledge and the classical model of science. Synthese. doi:10.1007/ s11229-008-9421-8.

Mancosu, P. (1991). On the status of proofs by contradiction in the seventeenth century. Synthese, 88, $15-41$.

Mancosu, P. (1996). Philosophy of mathematics and mathematical practice in the seventeenth century. New York/Oxford: Oxford University Press.

Mignucci, M. (1965). La teoria aristotelica della scienza. Firenze: Sansoni.

Mignucci, M. (1975). L'argomentazione dimostrativa in Aristotele. Commento agli Analitici Secondi. Padova: Antenore.

Mikkeli, H. (2002). Italian Aristotelians on the debate over the subalternation of medicine to natural philosophy. In C. Leijenhorst, C. Lüthy, \& J. M. M. H. Thijssen (Eds.), The dynamics of Aristotelian natural philosophy from antiquity to the seventeenth century (pp. 307-324). Leiden: Brill.

Ong, W. J. (1979). Ramus. Method, and the decay of dialogue. New York: Octagon Books.

Pascal, B. (1965). In L. Brunschvicq, P. Bourton, \& F. Gazier (Eds.), Oeuvres de Blaise Pascal. Vaduz: Krause Reprints.

Randall, J. H. (1961). The School of Padua and the emergence of modern science. Padova: Antenore. 
Scholz, H. (1930/1975). The ancient axioamtic theory. In J. Barnes et al. (Eds.) (1975) (pp. 50-64). (Trans. Die axiomatik der Alten. (1930). Blätter für Deutsche Philosophie, IV, 259-278.

Tatzel, A. (2002). Bolzano's theory of ground and consequence. Notre-Dame Journal of Formal Logic, 43, $1-24$.

Vasoli, C. (1984). La logica. In G. Folena, G. Arnaldi, \& M. Pastore Stocchi (Eds.), Storia della cultura veneta (Vol. III/3, pp. 35-73). Vicenza: Neri Pozza.

Verdonk, J. J. (1966). Petrus Ramus en de wiskunde. Assen: Van Gorcum.

Wolff, Chr. (1713). Vernünftigen Gedanken von den Kräften des menslichen Verstandes und ihrem richtigen Gebrauche in Erkenntnis der Wahrheit (1978). Hildesheim: Olms. 